\title{
Evaluation of stress among 100 Moroccan orthodontists
}

\author{
Lahcen Ousehal $^{1}$, Laila Lazrak ${ }^{2}$, Karima Hassani ${ }^{3}$ \\ ${ }^{1}$ Professor of Orthodontics, Department of Orthodontics, Faculty of Dentistry, Casablanca, Morocco; \\ ${ }^{2}$ Resident, ODF Service, Faculty of Dentistry, Casablanca, Morocco; \\ ${ }^{3}$ Student Graduate (MS), Faculty of Dentistry, Casablanca, Morocco. \\ E-mail: lahcen2228@yahoo.fr
}

Received 3 March 2011; revised 16 March 2011; accepted 18 March 2011.

\begin{abstract}
Stress is associated with many professions including dental surgery. It has been the subject of several studies. However, its evaluation in orthodontics has not been sufficiently studied. Some studies that have described the stressful aspects of dentistry have reported the involvement of orthodontists, but no studies have been conducted in Morocco. The purpose of this study is to evaluate professional stress in orthodontics in Morocco. We conducted a descriptive and sectional study through a survey distributed to one hundred private orthodontist practitioners in Casablanca, Morocco. Stress signs were observed in $44 \%$ of the orthodontists. The most prominent factors of stress in orthodontics are related to patients and time. Experience of practitioners has been identified as the only factor significantly influencing their perception of stress. Thus, clinical competence and proper management of practice are the best ways to deal with daily stress in orthodontic practice.
\end{abstract}

Keywords: Orthodontics; Stress; Time Management

\section{INTRODUCTION}

Dental work is known to be both physically and mentally demanding, which exposes the dentist to stress. Several studies have shown that dentistry $[1,4,5]$ generates more stress than other professions because of the nature and the working conditions of dentists.

The effects of professional stress have been well reported; in fact, several diseases have been linked to professional stress namely hypertension, disease of the coronary artery, alcoholism, drug addiction and suicide.

The purpose of this study is to assess the prevalence of stress among orthodontists, to identify the most stressful situations and the factors most often associated with this stress.

\section{MATERIALS AND METHODS}

We conducted a cross-sectional and descriptive study with dentists practicing orthodontics in Casablanca.

\subsection{People and Place of the Study}

Inclusion criteria:

1) Practitioners with a degree in orthodontics.

2) Practitioners who have their offices in Casablanca.

Exclusion criteria:

1) Practitioners who have not completed the entire survey.

On the list of orthodontists in Casablanca, a total of 116 were identified.

Ten orthodontists did not answer because of:

1) 2 false addresses

2) 1 orthodontist does not practice orthodontics anymore

3) 4 orthodontists have refused to participate in the study

4) 3 orthodontists were on leave

Thus, the sample was represented by 106 orthodontists; $86 \%$ of orthodontists in Casablanca have participated in the study.

The study was conducted using a survey comprising 78 questions, administered anonymously to orthodontists. Some have responded the same day, others preferred to complete it later. The latter were given a phone number for further explanations or information.

The survey consisted of 3 main parts:

1) The first part consisting of the assessment of stress and its impact on health.

2) The second part comprising the potential factors of stress and the practitioners' opinion of stress.

3) A third part asking for general information of practitioners.

\subsection{Analysis of the Questionnaire}

Professional stress has been evaluated using a list of potential stress factors; a total of 66 factors were included in the study. These were divided into six categories: patient, staff, time, income, reference and work. These categories were based on the classification system 
presented by Cooper et al..

Orthdontists were asked to indicate the severity of each "stressful" situation, and the frequency of its occurence.

The severity was classified using a Likert-type scale (ref) with 5 scores from a scale 1: not stressful to 5: very stressful.

Scores of severity of each situation were calculated to determine the most stressful aspects in orthodontic practice.

The frequency was recorded using a five-point scale; J: Never A: Rarely, M: Monthly, H: Weekly, Q: Daily

The score of frequency of each situation was calculated to determine the most common factors of stress in orthodontic practice.

We also asked the orthodontists to assess the stress of orthodontic practice using a scale ranging from 0 to 100 . This variable was considered as the overall score of professional stress.

The survey also included information on personal and professional data of the practitioner: age, sex, marital status, years of practice and type of practice. Six additional questions were included in the questionnaire to assess the prevalence of stress and its impact on health.

One investigator was responsible for this study.

\subsection{Statistical Analysis}

The statistical analysis was performed using SPSS $^{\circledR}$ (version 17.0, 2008)

\section{RESULTS}

Of the 106 questionnaires, 100 were used which represented a response rate of $94 \%$.

\subsection{Sample Description}

Our sample consisted of 31 women (31\%) and 69 men (69\%) (Table 1).

Table 1. Distribution according to age and years of practice.

\begin{tabular}{|c|c|c|c|c|c|}
\hline & & Man & Woman & Mean & SD \\
\hline & $\mathrm{N}$ & 69 & 31 & \multirow{5}{*}{37.7} & \multirow{5}{*}{10.3} \\
\hline \multirow{4}{*}{ Age } & $25-35$ & 26 & 39 & & \\
\hline & & & & & \\
\hline & $35-45$ & 5 & 19 & & \\
\hline & $45-55$ & 0 & 8 & & \\
\hline \multirow{3}{*}{ Years } & $1-10$ & 27 & 49 & \multirow{3}{*}{12.3} & \multirow{3}{*}{10.2} \\
\hline & $10-20$ & 04 & 18 & & \\
\hline & $20-30$ & 00 & 02 & & \\
\hline
\end{tabular}

Table 2. Prevalence of stress in the sample.

\begin{tabular}{ccc}
\hline Sex & Stressed & No stressed \\
\hline Women & 19 & 12 \\
Men & 25 & 44 \\
\hline
\end{tabular}

\subsection{Evaluation of Potential Factors of Stress}

Ranking of the most stressful situations based on the average severity scores (Table 3).

The analysis of the situation revealed 22 cases of 67 , receiving a severity score greater than or equal to 3.0.

The most stressful situation was dissatisfaction of the patient towards the care received, with an average of 4.04 and a standard deviation of 0.89 .

The situation with the lowest severity score was difficult y to communicate with staff, with an average of 3.02 and a standard deviation of 1.14.

Classification of situations most often stressful based on average frequency scores (Table 4).

Only the upper middle or equal to 3.0 were presented.

The analysis of these stressful situations indicated that 20 cases were a mean score of frequency greater than or equal to 3.0.

The most frequent situation was the treatment of adult patients; it has received an average of 4.29 and a standard deviation of 1.09 .

The situation with the lowest score was the frequency of patients coming late or missing the appointment, with an average of 3.00 and a standard deviation of 1.24.

Ranking of the most frequent and the most stressful situations (Table 5).

The most stressful situations and the most frequent ones were those with average score of severity and frequency greater than or equal to 3.0.

They were considered the most interesting factors of stress in the orthodontic practice.

This is due to the fact that those situations are the ones that are considered stressful by most orthodontists and occur more than once per month.

The analysis of all of these situations has classified 7 situations in which scores of frequency and severity are greater than or equal to 3.0.

Ranking of the six categories of stress factors (Table 6).

Factors of stress were divided according to the classification of Cooper in six categories: patient, staff, time, income, reference and work.

The average scores of these different categories were calculated using a severity scale.

The category with the highest mean score of stress was related to the factor "patient", with an average se- 
Table 3. Ranking of the most stressful situations based on the average severity scores*.

\begin{tabular}{|c|c|c|}
\hline Ranking & Mean & SD \\
\hline 1. Dissatisfaction of patients vis-à-vis the care received. & 4.04 & 0.89 \\
\hline 2. Treatment of adult patients. & 3.83 & 1.04 \\
\hline 3. Difficulties communicating with patients. & 3.74 & 1.02 \\
\hline 4. Pressure from patients to end the treatment. & 3.58 & 1.04 \\
\hline 5. Treatment of cases with a poor prognosis. & 3.52 & 1.01 \\
\hline 6. Execution of clinical tasks on difficult or uncooperative patients. & 3.51 & 1.14 \\
\hline 7. Patient coming late or missing appointments. & 3.49 & 1.05 \\
\hline 8. Motivation of patients with poor hygiene. & 3.47 & 1.00 \\
\hline 9. Dealing with unrealistic expectations of patients. & 3.39 & 1.34 \\
\hline 10. Patient late or miss their bonding session. & 3.31 & 1.03 \\
\hline 11. Patients with broken braces. & 3.28 & 1.22 \\
\hline 12. Having trouble winning patients' trust. & 3.19 & 1.43 \\
\hline 13. Legal disputes with patients. & 3.16 & 1.06 \\
\hline 14. Being overworked. & 3.10 & 1.05 \\
\hline 15. Acceptance of treatment outcome with compromise. & 3.09 & 1.19 \\
\hline 16. Being late. & 3.08 & 1.32 \\
\hline 17. Lack of payment of fees. & 3.07 & 0.99 \\
\hline 18. General practitioners challenging case management. & 3.06 & 0.89 \\
\hline 19. Inability to meet my own expectations. & 3.05 & 1.12 \\
\hline 20. Competition from other orthodontists. & 3.04 & 1.43 \\
\hline 21. Long hours of work. & 3.03 & 1.00 \\
\hline 22. Difficulty to get along with staff. & 3.02 & 1.14 \\
\hline
\end{tabular}

*Classified from 5 (most stressful) to 1 (stressful). Only averages greater or equal to 3 were considered.

Table 4. Classification of situations most often stressful based on average frequency scores*.

\begin{tabular}{lcc}
\hline \multicolumn{1}{c}{ Classement } & Moyenne & Ecart-type \\
\hline 1. Treatment of adult patients & 4.29 & 1.09 \\
2. Motivation of patients with poor hygiene. & 4.12 & 1.07 \\
3. Motivation of patients with poor hygiene. & 4.09 & 3.89 \\
4. Difficulty to get along with staff & 3.79 & 1.33 \\
5. Patients with broken braces & 3.66 & 1.14 \\
6. Difficulties communicating with patients & 3.52 & 1.04 \\
7. Patient coming late or missing appointments & 3.48 & 1.14 \\
8. Treatment of cases with a poor prognosis. & 3.39 & 1.45 \\
9. Long hours of work & 3.28 & 1.22 \\
10. Constant time pressure & 3.21 & 1.45 \\
11. Difficult work conditions & 3.19 & 1.22 \\
12. Emergency patients & 3.17 & 1.15 \\
13. Awareness that treatments are not permanent. & 3.10 & 1.34 \\
14. Overwork & 3.08 & 1.06 \\
15. Try to keep a program. & 3.05 & 1.33 \\
16. Patients transferred to another practice in your area & 3.03 & 0.89 \\
17. Patient expressing your fees are too high. & 3.02 & 1.22 \\
18. Obligation to train new assistants. & 3.01 & 1.43 \\
19. Difficulty to get along with staff & 3.00 & 1.16 \\
20. Patient coming late or missing appointments & & 1.45 \\
\hline
\end{tabular}

*Classified from 5 (most stressful) to 1 (stressful). Only averages greater or equal to 3 were considered. 
Table 5. Ranking of the most frequent and the most stressful situations.

\begin{tabular}{lcc}
\hline \multicolumn{1}{c}{ Facteur stressant } & Facteur stressant & Facteur stressant \\
\hline 1. Treatment of adult patients & 3.83 & 4.29 \\
2. Difficulties getting a long with patients. & 3.74 & 3.89 \\
3. Acceptance of treatment outcome with compromise. & 3.09 & 3.48 \\
4. Patient late or miss their bonding session & 3.31 & 3.52 \\
5. Patient coming late or missing the appointment. & 3.49 & 3.00 \\
6. Treatment of cases with a poor prognosis. & 3.52 & 3.48 \\
7. Long hours of work & 3.03 & 3.39 \\
\hline
\end{tabular}

Table 6. Ranking of the six categories of stress factors.

\begin{tabular}{lccc}
\hline \multicolumn{1}{c}{ Type of stress factor } & \# of factors in type & Severity average & Standard deviation \\
\hline Factors related to the patient & 17 & 3.74 & 0.78 \\
Factors related to time & 7 & 3.02 & 0.87 \\
Factors related to staff & 8 & 2.67 & 0.66 \\
Factor related to work & 19 & 2.45 & 0.98 \\
Factor related to income & 10 & 2.43 & 0.87 \\
Factors related to transfers & 6 & 2.42 & 0.75 \\
\hline
\end{tabular}

*Ranked from 5 (very stressful) to 1 (non stressful).

verity of 3.74 and a standard deviation of 0.78 . Followed by the time factor that has been classified as second category related to stress with an average of 3.02 and a standard deviation of 0.87 .

The category with the lowest average score of stress was related to factor "transfer", with an average of 2.42 and a standard deviation of 0.75 .

\section{EVALUATION OF THE DIFFERENT VARIABLES RELATED TO STRESS}

The overall score of stress was used as the dependent variable in a multiple regression analysis.

The remaining variables: age, sex, and duration of exercise were included as independent variables.

The analysis of the correlation by multiple regression of variables related to stress indicated the duration of exercise as the only characteristic that was positively related to stress $(\mathrm{p}<0.005)$. Other characteristics were negatively associated with stress $(p>0.005)$.

Table 7. Correlation and multiple regression of different variables related to stress*.

\begin{tabular}{ccc}
\hline $\begin{array}{c}\text { Variable related to } \\
\text { stress }\end{array}$ & Nature of the correlation & P-value \\
\hline Global stress & Negative & 0.001 \\
Age & Negative & 0.005 \\
Sex & Negative & 0.008 \\
Experience & Positive & 0.004 \\
\hline
\end{tabular}

*Overall $\mathrm{R}^{2}=0.345$.

\section{DISCUSSION}

This study was exhaustive because it concerned all the orthodontists of Casablanca.

The study showed a high rate of response, 94.3\%.

\subsection{Overall Professional Stress among Ortho- dontists}

The prevalence of stress among dentists has been estimated to 60\% in the United Kingdom (MYERS1), 59.7\% in Denmark (Moore and coll [2]), and 48\% depending Vanagas and coll [3] (Lituania).

The prevalence of stress among orthodontists in Casablanca is less important than in other countries, since it has been estimated to $44 \%$. These results demonstrate that the phenomenon of stress is present in orthodontic practices.

But this result is still higher compared to other studies such as in Holland, where only $13 \%$ to $16 \%$ of dentists suffer from professional stress (Gorter and coll [4]).

\subsection{Factors of Occupational Stress among Or- thodontists}

A similar study was conducted among Canadian orthodontists [5]. The most frequent factors of stress were almost identical in both studies. These factors include the treatment of adult patients, patients coming in late and motivating patients with poor hygiene and/or decalcification.

Too much work, the difficulty to agree with staff and with patients was also among the most frequent factors of stress. These were also reported as major stress factors 
in an American study [6].

Regarding the most stressful aspects, the three factors most strongly affected were: patient dissatisfaction vis-à-vis the care received, treatment of adult patients, and the lack of communication with patients. Compared with the Canadian study [5], only the first factor has been ranked among the top three most stressful factors. The remaining factors are: the execution of clinical tasks on difficult or uncooperative patients that have fallen behind.

Other factors of stress that are similar to the Canadian [5] study are: patients late or missing their bonding sessions, patients with broken appliances, the constant pressure of time, acceptance of treatment outcome with compromises, treatment of cases with a poor prognosis, and the medico-legal cases.

Many similarities were also observed between the results of this study and those reported in general dentistry that also made reference to the factors leading the most to stress, mainly: the dissatisfaction of patients, patients with difficult or uncooperative patients and emergency.

Two situations have been reported as being stressful in general dentistry, but have not proven highly stressful in orthodontics, these included the perception of the practitioner as a source of pain and frequent decision making.

However, many other situations have been reported as stressful in the orthodontic population, but they are not common in studies of general dentistry. These include: pressure from patients and/or parents to remove the devices before the end of treatment, the awareness that treatment is not permanent, general practitioners challenging case management, and deal with unrealistic expectations of patients. This suggests that stress in orthodontics is associated to the particularity of the specialty in addition to the general characteristics of dental practice.

Despite the many similarities between the results of the study and the Canadian study [5], analysis of the most concerned factors in orthodontics showed a big difference.

The four largest factors of stress among Canadian orthodontists were those related to time management $[5,8]$. Orthodontists in Casablanca ranked this factor second after the factor "patient".

Indeed, treatment of adult patients, the difficulty of communication with patients require more attention and therefore more "work hours", just as patients coming late or missing their meeting bonding and patients missing their appointments also generate disturbances at the level of "hours".

So all these factors cause an increase in working hours, leading orthodontists to be under stress.

This result is consistent with that of Vander Hulst [9] which proved an association between long working hours and adverse health manifested by fatigue, stress and general diseases such as diabetes and cardiovascular disease.

\subsection{Factors Affecting the Occupational Stress in Orthodontics}

Although the difference between groups was low, analysis of the scores of the six factors of stress ranked the factor in relation to the patient first of the list, followed by the one related to time.

A similar result was reported by numerous foreign studies like those conducted with Lithuanian [10] and South Korea [11] dentists.

General dentistry Doctors [10-12] also ranked these two factors as most important.

The study on Canadian orthodontists [5] revealed similar results, and classified these two factors as the main source of stress.

These results showed the importance of these factors and suggest that orthodontists who want to reduce stress should first improve their management skills with their patients and that of time of their work.

\subsection{The Role of Various Personal Characteristics and Practice on Stress in Orthodontics}

Personality and individual differences are known to have important influences on the stress response. Indeed, marked differences were observed in response to the 66 potential stress factors. Each case was classified as "very stressful" by at least one orthodontist and not as "stressful" by at least one other. Similarly for frequency, since facing the same situation at least two orthodontists have responded differently.

But these influences played a larger role in the estimation of stress in orthodontics, whose answers have included almost the entire scale and have reached 90 points on the scale of 100 points.

In our study, age, sex and years of practice have been described in a final regression model to explain some of the variation of occupational stress.

These characteristics have been reported as affecting the relationship of stress in global dentistry [7] and orthodontics [5].

The duration of exercise was reported as the only factor significantly associated with stress according to the regression model. This suggests that as and when the duration of exercise increases, stress decreases.

So it is reasonable to assume that orthodontists practicing for several years become more knowledgeable and more aware of stress, and therefore more likely to take steps to manage it.

It is interesting that the age and sex were not significant in our study, although there is a possible interrela- 
tionship between these two factors and stress in other studies [13].

Overall, this regression model could not explain all the variation in scores of job stress.

This suggests that there are other factors such as personality that may influence stress.

What we can conclude at the end of this survey is that there is a wide variation in the assessment of potential stress factors and the overall estimate of occupational stress in orthodontics.

Similarly, other factors seem to have a greater effect on the stress than the characteristics assessed by this survey.

Several limitations should be taken into account when interpreting the results of this study. Notably, the fact that the results reflect only the data collected by questionnaire and low sample size must be increased and diversified.

Thus, any longitudinal studies are strongly needed to examine changes in environmental factors at work.

\section{CONCLUSIONS}

In our work, we studied the source, the frequency and the severity of stress experienced by orthodontists.

Marked differences were found between orthodontists in Casablanca in the evaluation of factors of stress and the overall estimate of occupational stress in orthodontics.

Thus, $44 \%$ of orthodontists suffer from chronic stress.

The most relevant factors of stress to orthodontic practice based on high average severity and frequency are factors related to the patient $(3.74 \pm 0.78)$ and those related to time (3.07 \pm 0.87$)$.

The analysis of the correlation by multiple regression of variables related to stress identified only the duration of exercise as a factor significantly influencing the perception of stress. Indeed, the previously installed orthodontists feel less stress compared to younger people in the profession.

Clinical competence and the proper management of orthodontic practice remains a real cornerstone for re- ducing stress in daily orthodontic practice.

\section{REFERENCES}

[1] Myers, H.L. (2004) It's difficult being a dentist': Stress and health in the general dental practitioner. British Dental Journal, 197, 89-93. doi:10.1038/sj.bdj.4811476

[2] Moore R. (2001) Dentists' perceived stress and its relation to perceptions about anxious patients. Community Dentistry and Oral Epidemiology, 29, 73-80.

[3] Vanagas G. (2004) Do age, gender and marital status influence job strain development for general practitioner? Medicina (Kaunas), 40, 1014-1018.

[4] Coomber S. (2004) Stress in UK intensive care unit doctors. British Journal of Anaesthesia, 92, 151-152. doi:10.1093/bja/aeh507

[5] Roger E.A. (2001) Stress-related suicide by dentists and other health care workers. Journal of the American Dental Association, 132, 786-794.

[6] Heying S.S. (2007) The success of orthodontic satellite practice. Angle Orthodontist, 77, 875-880. doi:10.2319/032706-125

[7] Calman M. (2001) Mental health and stress in the workplace. Social Science \& Medicine, 52, 499-507. doi:10.1016/S0277-9536(00)00155-6

[8] Dowell A.C. (2001) A survey of job satisfaction, sources of stress and psychological symptoms among New Zealand health professionals. New Zealand Medical Journal, 114, 540-543.

[9] Gilmour J. (2005) An assessment of career satisfaction among a group of general dental practitioners in Stafforshire. British Dental Journal, 198, 701-704. doi:10.1038/sj.bdj.4812387

[10] Gorter R.C. (2006) Job resources in Dutch dental practice. International Dental Journal, 56, 22-28.

[11] Jeong S.H. (2006) Factors related to job satisfaction among South Korean dentists. Community Dentistry and Oral Epidemiology, 34, 460-466. doi:10.1111/j.1600-0528.2006.00297.x

[12] Simoens S. (2002) Job satisfaction, work-related stress and intentions to quit of Scottish GPS. Scottish Medical Journal, 47, 80-86.

[13] Tyssen R. (2005) The relative importance of individual and organizational factors for the prevention of job stress during internship. Medical Teacher, 27, 726-731. doi:10.1080/01421590500314561 